\title{
Relações entre nutrientes na fase sólida e solução de um latossolo durante o primeiro ano nos sistemas plantio direto e convencional
}

\author{
Relationship between nutrients in solid phase and soil solution of a "latossolo" (oxisol) in the first year \\ of no-tillage and conventional systems
}

\author{
Leandro Souza da Silva ${ }^{1}$ Humberto Bohnen ${ }^{2}$
}

\section{RESUMO}

Somente a análise dos nutrientes da fase sólida pode não representar a disponibilidade de nutrientes porque não considera a sua relação com a solução do solo. Realizouse um trabalho visando a estudar a relação entre nutrientes na fase sólida e na solução de um Latossolo durante o primeiro ano da instalação dos sistemas plantio direto e convencional de preparo do solo. Foram utilizadas 144 amostras coletadas nas profundidades de $0-2,5 \mathrm{~cm}, 2,5-5,0 \mathrm{~cm} 5,0-15,0 \mathrm{~cm}$ antes $e$ aos 2, 6 e 12 meses depois da instalação dos sistemas de preparo, exceto para carbono, para o qual utilizaram-se 24 amostras coletadas aos 12 meses após a instalação, em um experimento localizado no município de Santo Ângelo-RS, conduzido em sucessão aveia-preta/soja. Avaliaram-se carbono e nutrientes (Ca, $\mathrm{Mg}, \mathrm{Mn}, \mathrm{K}$ e P) da fase sólida e da solução do solo, obtendo-se a relação entre eles por meio da análise de regressão. Os resultados indicaram que os teores de $\mathrm{Ca}, \mathrm{Mg}$, $\mathrm{Mn}$, K e P na solução do solo estão relacionados com os da fase sólida, com exceção do carbono orgânico.

Palavras-chave: dinâmica de íons, preparo do solo, características químicas.

\section{ABSTRACT}

Nutrient availability should not be represented only by the chemical analysis of the solid phase, which does not include its relation with the soil solution. A study was carried out to investigate the relationship between nutrients in solid phase and soil solution of a "Latossolo Roxo"(Oxisol) from Santo Ângelo, Rio Grande do Sul state, during the first year after the installation of the no-tillage and conventional systems an oat-soybean rotation. It was evaluated 144 soil samples sampled before and 2, 6, and 12 months after installation (except carbon that was used 24 samples 12 months after installation) and from three depths $(0-2.5 \mathrm{~cm}, 2.5-5.0 \mathrm{~cm}$ and 5.0-15.0cm). Carbon and nutrient (Ca, Mg, Mn, K e P) were evaluated in solid phase and soil solution, and the relation between them was obtained through regression analysis. The results indicated that $\mathrm{Ca}, \mathrm{Mg}, \mathrm{K}, \mathrm{Mn}$, and $\mathrm{P}$ evaluated in soil solution were significantly related to those of the solid phase, excepted for carbon.

Key words: ionic dynamics, soil tillage, and chemical characteristics.

\section{INTRODUÇÃO}

Os trabalhos em fertilidade sob sistemas conservacionistas de preparo do solo, como o sistema plantio direto, sugerem um acúmulo na camada superficial, ao longo do tempo, de carbono orgânico, nitrogênio total e de nutrientes tais como fósforo, potássio, cálcio e magnésio, em comparação ao sistema convencionalmente utilizado (preparo do solo com aração e gradagens) (HAVLIN et al., 1990; WOOD et al., 1991). Segundo ELTZ et al. (1989), o acúmulo de carbono e nutrientes na camada superficial do solo sob sistema plantio direto está associado à deposição de resíduos de culturas em superfície e à aplicação de fertilizantes em uma pequena profundidade, sendo que sistemas de cultivo envolvendo preparos com mobilização intensa do solo proporcionam uma distribuição mais uniforme de nutrientes na camada arável.

Entretanto, apesar de possíveis diferenças na composição do solo sob diferentes sistemas de

\footnotetext{
${ }^{1}$ Departamento de Solos, Centro de Ciências Rurais (CCR), Universidade Federal de Santa Maria (UFSM), 97105-900, Santa Maria, RS, Brasil. E-mail: leandro@smail.ufsm.br . Autor para correspondência.

${ }^{2}$ Departamento de Solos, Universidade Federal do Rio Grande do Sul (UFRGS), Porto Alegre, RS, Brasil. E-mail: humbertobohnen@uol.com.br.
} 
preparo, a disponibilidade dos nutrientes às plantas dependerá da dinâmica dos elementos na fase sólida e na solução. A fase sólida do solo é uma mistura heterogênea de compostos orgânicos e minerais, cujas superfícies apresentam cargas permanentes ou pHdependentes, que estão em equilíbrio com os íons de carga oposta presentes na solução do solo, formando um sistema denominado complexo de troca do solo (SPOSITO, 1989). É a fase sólida do solo, portanto, que irá determinar o ambiente químico às raízes das plantas, afetando a composição e a atividade dos íons na solução do solo por meio do princípio de produto de solubilidade e de reações de sorção (ADAMS, 1974). Todavia, a quantidade de cargas na fase sólida de um solo pode ser alterada, quando utilizado o sistema plantio direto, pelo incremento do teor de matéria orgânica ao longo do tempo, devido ao aumento da carga protônica líquida $(\sigma \mathrm{H})$ do solo (SALET, 1994). Pelo aumento da $\sigma \mathrm{H}$ negativa, com a maior dissociação de prótons dos grupos funcionais da matéria orgânica, ocorre uma compensação pela carga dos íons de carga oposta, aumentando a capacidade do solo em reter e trocar cátions (CTC).

Assim, o sistema plantio direto deve alterar a dinâmica dos nutrientes no solo em relação ao sistema de preparo convencional. Esse efeito é facilmente detectado após algum tempo que o solo esteja submetido ao sistema plantio direto, mas é provável que algumas alterações na relação da fase sólida com a solução já ocorram desde a sua implantação, com reflexos importantes na disponibilidade dos nutrientes às plantas. Outro aspecto importante a ser considerado é que somente a análise dos teores de nutrientes no solo (caracterização da fase sólida) para avaliar os sistemas de preparo não representa, necessariamente, alterações na disponibilidade para as plantas, pois o comportamento dos íons no solo depende da relação dinâmica entre a fase sólida e a solução do solo (SALET, 1994). Por isso, a análise dos nutrientes na solução do solo pode ser um indicador sensível, aliado à análise da fase sólida, para melhor avaliar e acompanhar alterações a partir da fase de implantação dos sistemas de preparo (SILVA, 1996). O presente trabalho teve o objetivo de avaliar as relações entre nutrientes na fase sólida e na solução do solo para um Latossolo durante o primeiro ano da instalação do sistema plantio direto sob área com sistema convencional de preparo do solo.

\section{MATERIAL E MÉTODOS}

Para esse estudo, utilizaram-se 144 amostras de solo de um experimento instalado no município de Santo Ângelo-RS, classificado como um Latossolo
Vermelho distroférrico típico (EMBRAPA, 1999), pertencente à Unidade de Mapeamento Santo Ângelo (BRASIL, 1973), em sucessão aveia-preta (Avena strigosa)/soja (Glicine max), cujo manejo e condução experimental estão descritos em SILVA (1996). As amostras foram coletadas em parcelas de 24 x $25 \mathrm{~m}$ conduzidas sob sistemas plantio direto (semeadura sobre a resteva da cultura anterior) e convencional (semeadura após uma lavração e duas gradagens), em dois níveis de fertilização para cada sistema. No primeiro, uma parcela de cada tratamento recebeu calcário e fertilizantes antes da instalação do experimento e manutenção da fertilidade por meio de adubação a lanço, para a instalação das culturas de acordo com as recomendações da CFS (1995). No segundo outra parcela foi conduzida com a fertilidade estabelecida por manejos anteriores à instalação dos tratamentos sob condição de lavoura convencional.

O solo foi amostrado após o cultivo de aveiapreta (antes da instalação dos sistemas de preparo), dois meses após o primeiro preparo convencional (40 dias após a semeadura da soja), seis meses após o primeiro preparo (após a colheita da cultura da soja) e 12 meses após o primeiro preparo (após a colheita da cultura da aveia), completando o acompanhamento dos sistemas de um ano agrícola, exceto para o carbono, para o qual foram utilizadas 24 amostras da coleta aos 12 meses da instalação dos sistemas. As amostras foram obtidas abrindo-se seis trincheiras aleatoriamente nas parcelas e coletando-se porções de solo com auxílio de espátulas nas profundidades de 0,0 a $2,5 \mathrm{~cm} ; 2,5$ a $5,0 \mathrm{~cm}$ e 5,0 a 15,0cm, onde a cada duas trincheiras formou-se uma amostra composta, totalizando três amostras por parcela.

As amostras foram secadas ao ar, moídas em rolo e tamisadas em malha de $2 \mathrm{~mm}$ de diâmetro. Uma porção da amostra foi utilizada para análise do carbono total (Walkley-Black), dos teores de Ca, Mg e Mn trocáveis ( $\mathrm{KCl} 1 \mathrm{~mol} \mathrm{~L}^{-1}$ ), de $\mathrm{K}$ e P extraíveis (Mehlich-1) na fase sólida, conforme metodologias descritas em TEDESCO et al. (1995). Outra porção foi destinada à extração da solução do solo por centrifugação a 4.000rpm por 30 minutos, pelo método de ELKAHATIB et al. (1987), conforme descrito em SILVA (1996). Na solução, foram analisados os teores de Ca, Mg e Mn por espectrometria de absorção atômica, de K por fotometria de chama e de P pelo método MURPHY \& RILEY (1962), este último após filtragem em filtro 0,2 $\mu \mathrm{m}$ versapor (Gelman Sciences Inc.). O teor de carbono orgânico solúvel foi analisado na quarta amostragem por colorimetria (580nm), após digestão por $4 \mathrm{~h}$ a $60^{\circ} \mathrm{C}$, com uma mistura sulfocrômica de $\mathrm{K}_{2} \mathrm{Cr}_{2} \mathrm{O}_{7} 1,25 \mathrm{~mol} \mathrm{~L}^{-1}$ contendo $80 \mathrm{~mL}$ de $\mathrm{H}_{2} \mathrm{SO}_{4}$ 
concentrado (relação amostra:mistura de 1:1) e uso de um fator 1,35 em relação à curva de glicose (correlacionado para solos do RS ( $\mathrm{r}=0,997)$, com o método descrito em MOORE (1985).

Os valores obtidos nos dois sistemas para os parâmetros Ca, Mg, K, Mn, C orgânico e P avaliados na fase sólida foram relacionados com os valores na solução do solo e realizada análise de regressão entre as variáveis, com significância em nível de probabilidade de erro de $5 \%$.

\section{RESULTADOS E DISCUSSÃO}

O sistema plantio direto apresentou maiores teores de carbono, fósforo e potássio na fase sólida e cálcio, magnésio, fósforo e potássio na solução do solo na camada superficial ( 0 a 2,5cm), já durante o primeiro ano da instalação dos sistemas (dados não apresentados). O acúmulo de nutrientes na camada superficial do plantio direto em relação ao convencional já é amplamente conhecido na literatura, com trabalhos realizados comparando os sistemas em efeitos temporais e de profundidade no perfil do solo (ELTZ et al, 1989; HAVLIN et al., 1990; WOOD et al.; 1991; SALET, 1994). Este comportamento é devido à aplicação superficial de fertilizantes e corretivos e à não mobilização do solo, sendo os resultados assim discutidos em SILVA(1996). Dessa forma, o enfoque deste trabalho foi a relação entre os teores dos nutrientes obtidos na fase sólida e na solução do solo.

As relações entre os teores de cálcio e de magnésio da fase sólida com os da solução do solo foram significativas $\left(\mathrm{r}^{2}=0,61^{* *}\right.$ e $0,54^{* *}$ respectivamente), com comportamento semelhante para os dois sistemas de preparo (Figuras 1a e 1b). Entretanto, já pode ser observado um provável efeito do sistema plantio direto, com a presença de algumas amostras com maiores teores de Ca e Mg na solução do solo para valores similares ao convencional na troca, que afetaram o coeficiente de determinação para a relação obtida. Tal comportamento indica alterações na dinâmica destes nutrientes e que a análise química dos teores trocáveis do cálcio e do magnésio no sistema plantio direto podem não representar, necessariamente, a mesma disponibilidade desses nutrientes para as plantas em relação ao sistema convencional. Isto porque a principal forma de suprimento desses nutrientes ocorre por fluxo de massa, sendo que e a concentração na solução é fator preponderante nesse processo (VARGAS et al., 1983).

Uma hipótese possível para esse comportamento pode estar relacionada com a determinação analítica do teor trocável desses elementos, superestimando os valores que estão em real equilíbrio com a solução do solo, visto que, para a análise dos teores destes elementos na solução do solo, não se utilizam extratores químicos no processo, o que proporciona certa garantia na obtenção da concentração dos elementos na solução do solo em equilíbrio com a fase sólida. Segundo SPOSITO (1989), a adsorção de Ca e Mg no solo ocorrem pela formação de complexos denominados de esfera externa, ou seja, de natureza não-específica com os grupos funcionais de superfície. Entretanto, uma mudança na dinâmica da matéria orgânica ao longo do tempo no sistema plantio direto deve alterar também a composição das cargas negativas do solo, resultando em diferentes grupos funcionais de diferentes afinidades e em conseqüentes alterações no equilíbrio entre as fases sólida e líquida. Também pode ser observado na figura 1 que o ajuste matemático das relações obtidas apresenta equações com valores do intercepto da reta ("a”) negativos para os dois elementos. Considerando a limitação de não existirem pontos com baixos teores de cálcio e magnésio trocáveis nas amostras avaliadas, esse ajuste indica a possibilidade de as concentrações de cálcio e magnésio na solução do solo serem muito próximas a zero quando os teores desses nutrientes estiverem abaixo de 2 e $1 \mathrm{cmol} \mathrm{dm}^{-3}$, respectivamente.

O potássio na solução do solo apresentou relação significativa $\left(r^{2}=0,94^{* *}\right)$ com o teor extraível da fase sólida (Figura 2a), com comportamento idêntico para os dois sistemas de preparo do solo. Também o potássio é adsorvido no solo por complexos de esferaexterna, entretanto com menor afinidade pela superfície do que Ca e Mg (SPOSITO, 1989). Apesar de a relação ser idêntico para os dois sistemas de preparo, aplicações superficiais de adubos potássicos e a não mobilização do solo têm proporcionado a manutenção de maiores teores de potássio extraíveis na camada superficial do sistema plantio direto (ELTZ et al, 1989; SILVA, 1996). Assim, ao considerarmos uma alteração para o teor extraível entre sistemas de preparo do solo acompanhada de alterações nos teores de potássio na solução do solo, também há uma alteração na disponibilidade do nutriente, visto que o teor de potássio na solução do solo é fator determinante no processo de difusão, como suprimento do nutriente às plantas (COREY, 1973). De outra maneira, maiores teores de potássio na superfície podem ser fator desfavorável para o sistema plantio direto, no que se refere às perdas do nutriente juntamente com a água e sedimentos. Também existe a possibilidade de a camada superficialdo solo secar rapidamente, quer por evaporação ou por intensa absorção radicular, o que, conseqüentemente, reduziria a absorção do nutriente, apesar dos elevados teores nessa camada. 

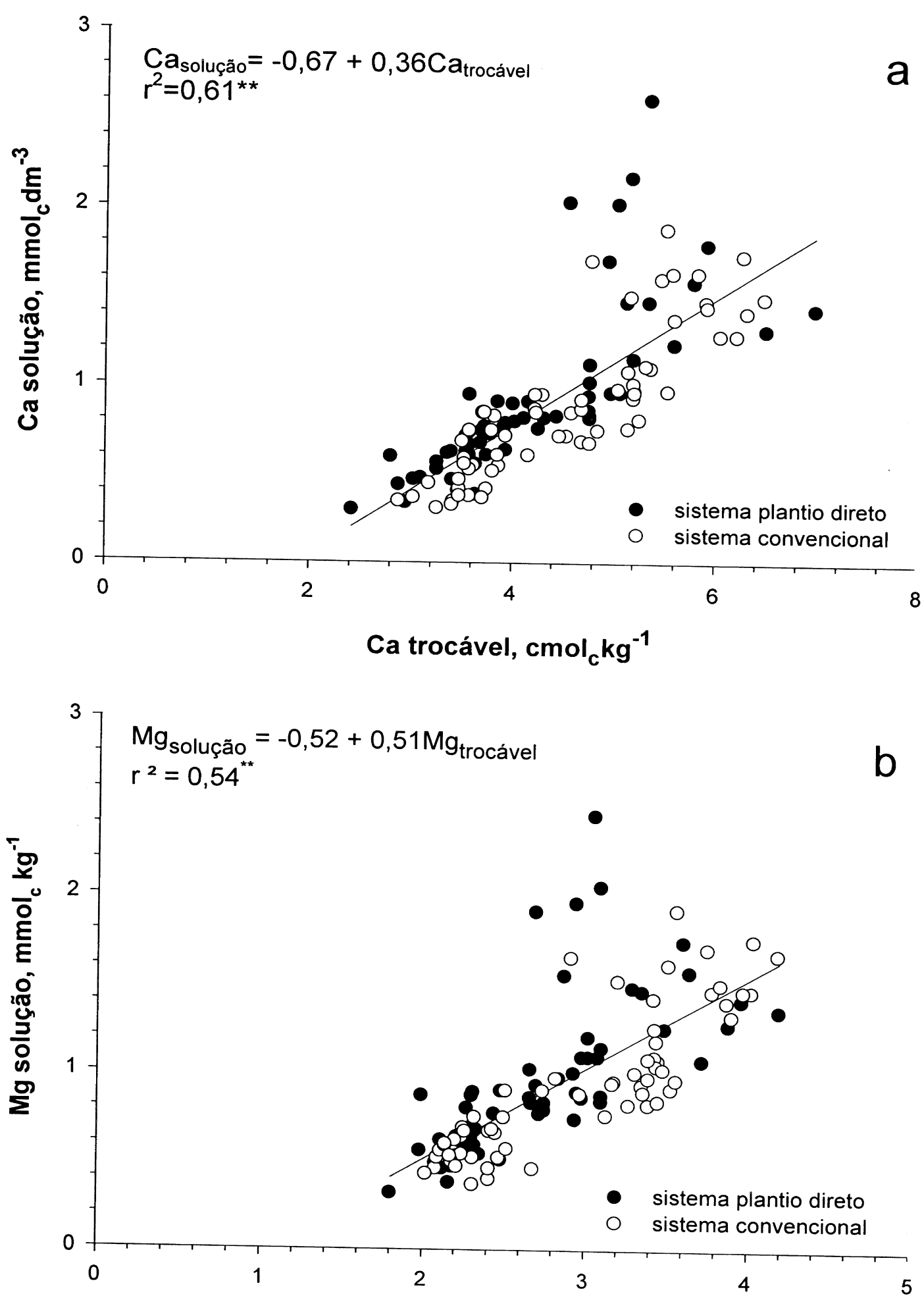

Mg trocável, $\mathrm{cmol}_{\mathrm{c}} \mathbf{k g}^{-1}$

Figura 1 - Relação entre teores de Ca (a) e Mg (b) trocáveis na fase sólida e na solução de amostras coletadas em três profundidades e em quatro épocas, durante o primeiro ano em que um latossolo foi submetido aos sistemas plantio direto e convencional (n = 144).

Ciência Rural, v.36, n.4, jul-ago, 2006. 
Ao contrário do Ca e do Mg, o melhor ajuste para a dinâmica do potássio foi uma função quadrática, cujo comportamento pode ter relação com a influência da variação dos teores de cálcio e magnésio entre as amostras de solo e da sua relação com o potássio na afinidade dos elementos pelos sítios de troca no solo (LIMA, 1993). De qualquer modo, a função obtida para o Latossolo $\left(\mathrm{K}_{\text {solução }}=0,42 \mathrm{~K}_{\text {troca }}+0,33 \mathrm{~K}_{\text {troca }}{ }^{2}\right)$ pode ser útil em estudos que envolvam modelos mecanísticos de absorção de potássio (MEURER, 1991 e BARBER, 1995) e que necessitem dos valores dos teores de potássio extraível na solução e o poder tampão de K.

Também houve relação significativa entre o teor de manganês na solução do solo e o teor trocável (Figura 2b), também de modo semelhante para os dois sistemas de preparo do solo, cujo comportamento foi mais bem ajustado para o modelo quadrático $\left(\mathrm{Mn}_{\text {solucão }}=\right.$ $0,06 \mathrm{Mn}_{\text {troca }}+0,23 \mathrm{Mn}_{\text {troca }}{ }^{2}$ ). Esse elemento, em certas condições, apresenta a característica de toxicidade ou deficiência, sendo grandemente afetado pelo material de origem do solo, pelo $\mathrm{pH}$, condições redox, teor de matéria orgânica e pela atividade microbiana (BATAGLIA, 1988). O modelo quadrático ajustado para o elemento pode ser resultado do efeito do $\mathrm{pH}$ do solo (valores a partir de 0,50 cmoc $_{\mathrm{c}} \mathrm{kg}^{-1}$ estão associados com valor de $\mathrm{pH}$ inferior a 5,5, diminuindo sua solubilidade) e, talvez, das condições de oxidação nos períodos de amostragem, que variaram entre as amostragens e que influenciam o comportamento do manganês no solo.

Os valores de carbono na solução do solo não apresentaram relação significativa com o carbono total (Figura 3a). Embora não haja um equilíbrio químico diretamente envolvido entre o carbono da fase sólida e o da solução do solo, espera-se que a maior quantidade de carbono total suporte uma maior atividade biológica, que proporcione maior quantidade de compostos orgânicos solúveis, determinando maiores teores na solução do solo. Entretanto, a falta de uma relação poderia ser explicada pelo manuseio das amostras antes da análise, tendo em vista que, para a obtenção dos valores de carbono solúvel, foi necessário um determinado tempo entre a coleta e a extração da solução do solo (7 a 10 dias), e que como as amostras encontravam-se com diferentes teores de umidade no momento da coleta, os resultados do carbono na solução do solo podem ter sido afetados por um período de incubação dessas amostras. Isso permite sugerir que determinações de carbono orgânico dissolvido na solução do solo (da mesma forma, isso deve ocorrer com sulfato e nitrogênio, tendo em vista a semelhança entre as formas que controlam suas dinâmicas no solo) devam ser realizadas imediatamente após a coleta do solo para controlar a ocorrência de possíveis alterações que possam comprometer a interpretação dos resultados obtidos na solução do solo.

Os valores de fósforo da solução do solo relacionaram-se significativamente com os extraídos da fase sólida (Figura 3b) de modo semelhante para os dois sistemas de preparo do solo. Entretanto, a relação significativa entre o fósforo da solução com o extraível $\left(r^{2}=0,53^{* *}\right)$, leva em consideração toda a amplitude encontrada, principalmente devido às aplicações superfícies de fertilizante fosfatado que proporcionaram acúmulo de fósforo nos primeiros centímetros do sistema plantio direto (dados não apresentados). Dessa forma, existe uma grande concentração de pontos na faixa de 5 a $25 \mathrm{mg} \mathrm{kg}^{-1}$ de $\mathrm{P}$ extraível, mas com um comportamento disperso que explica o menor coeficiente de determinação encontrado que indica uma restrição no emprego da equação obtida para determinar o teor de fósforo na solução do solo na faixa de P extraível considerada. A maior dispersão de pontos para a relação do $\mathrm{P}$ na solução com o P na fase sólida poderia ser atribuída à grande afinidade deste elemento pelos sítios de adsorção (complexo de esferainterna), que pode ter influenciado tanto a determinação dos teores em solução como os teores extraíveis da fase sólida, aumentando a variabilidade dos valores determinados.

Não foram detectadas diferenças sensíveis na dinâmica dos nutrientes entre os dois sistemas de preparo avaliados no primeiro ano, provavelmente devido à pouca alteração no teor de carbono orgânico entre os sistemas no período de avaliação (dados não apresentadas). Espera-se que, em períodos maiores de tempo devam ocorrer maiores alterações no teor de carbono, que assim proporcionarão maiores efeitos sobre a dinâmica dos nutrientes no solo e a sua disponibilidade às plantas. SALET (1994), comparando o sistema plantio direto com o sistema convencional ao longo do ciclo da cultura do milho, após oito anos da instalação dos sistemas, encontrou no sistema plantio direto $50 \%$ mais de carbono total e $110 \%$ mais mais carbono na solução do solo e menor concentração de cátions (Ca, Mg e K) na solução do solo, com aumento da quantidade de potássio retido na troca, após as adubações, devido à maior CTC nesse sistema a qual é resultado do maior teor de matéria orgânica.

\section{CONCLUSÃO}

Houve relação significativa entre os valores de cálcio, magnésio, potássio, manganês e fósforo da fase sólida com os avaliados na solução do solo para o latossolo, durante o primeiro ano em que foi submetido aos sistemas plantio direto e convencional. Para o carbono, essa relação não foi significativa. 


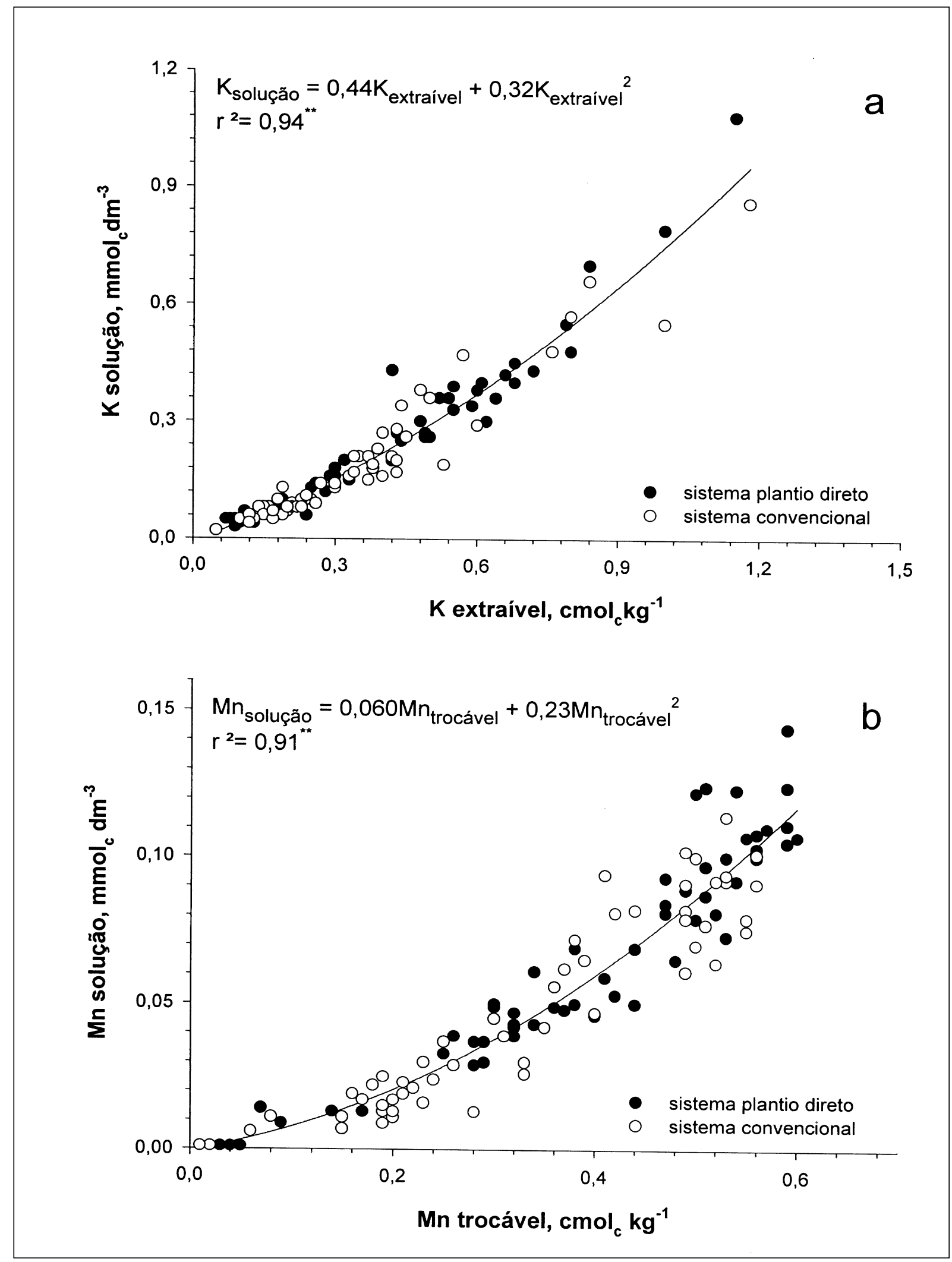

Figura 2 - Relação entre teores de K (a) e Mn (b) trocáveis na fase sólida e na solução de amostras coletadas em três profundidades e em quatro épocas, durante o primeiro ano em que um latossolo foi submetido aos sistemas plantio direto e convencional (n = 144).

Ciência Rural, v.36, n.4, jul-ago, 2006. 

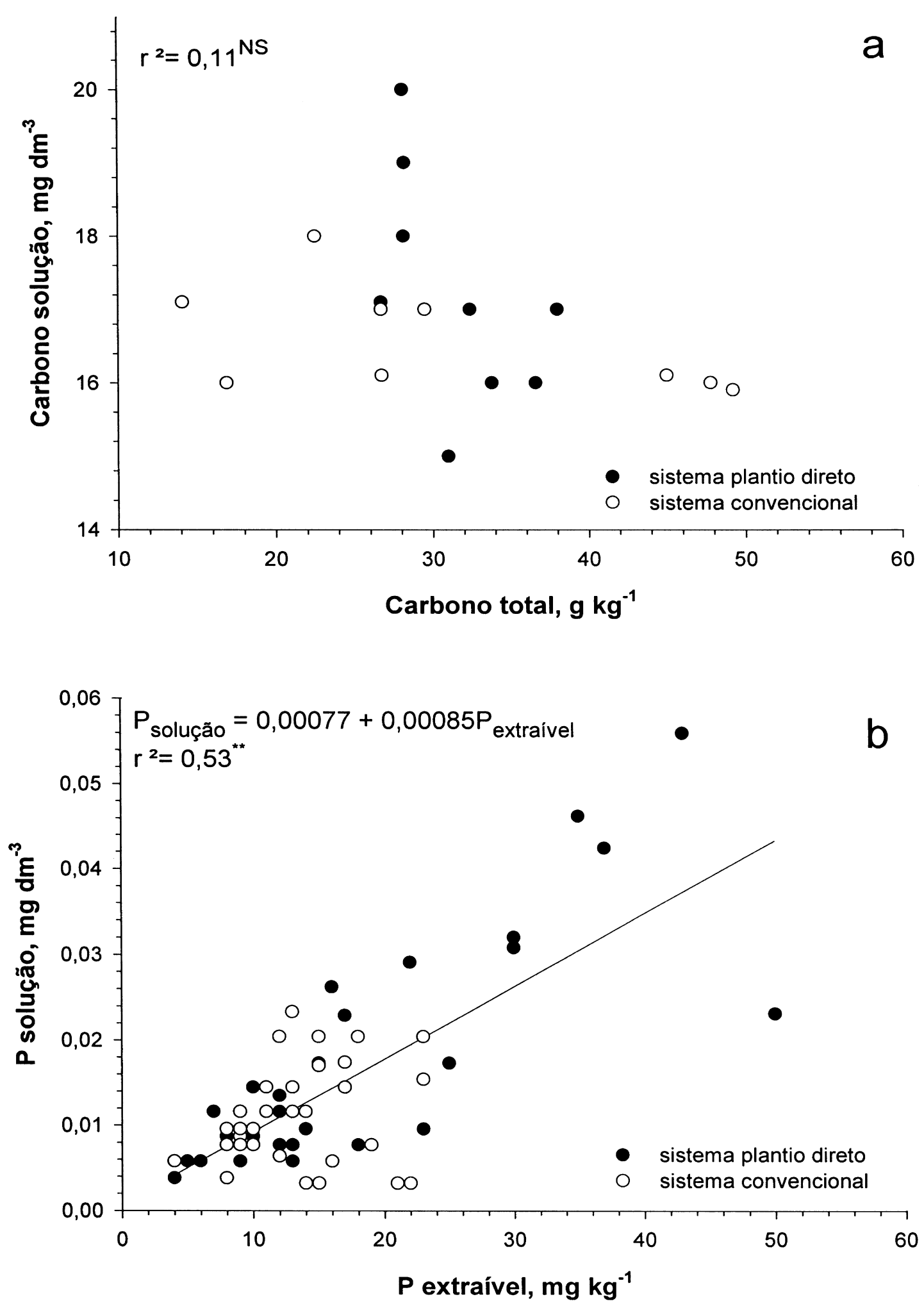

Figura 3 - Relação entre teores de C (a) e P (b) trocáveis na fase sólida e na solução de amostras coletadas em três profundidades e em quatro épocas, durante o primeiro ano em que um latossolo foi submetido aos sistemas plantio direto e convencional ( $\mathrm{n}=24$ e $n=144$ para carbono e fósforo, respectivamente). 


\section{REFERÊNCIAS}

ADAMS, F. Soil solution. In: CARSON, E.W. (Ed). The plant root and its environment. Charlottesville: University of Virginia, 1974. Cap.15, p.441-481.

BARBER, S.A. Soil nutrient bioavailability: a mechanistic approach. 2.ed. New York: John Wiley, 1995. 414p.

BATAGLIA, O.C. Micronutrientes: disponibilidade e interações. In: BORKERT, C.M.; LANTMANN, A.F. Enxofre e micronutrientes na agricultura. Londrina: EmbrapaCNPSo/IAPAR/SBCS, 1988. Cap.6, p.121-132.

BRASIL. Ministério da Agricultura. Levantamento de reconhecimento dos solos do Estado do Rio Grande do Sul. Recife: Serviço Nacional de Pesquisa Agropecuária, Divisão de Pesquisa Pedológica, 1973. 431p. (Boletim Técnico, 30).

COMISSÃO DE FERTILIDADE DO SOLO - CFS - RS/SC. Recomendações de adubação e calagem para os estados do Rio Grande do Sul e Santa Catarina. 3.ed. Passo Fundo: SBCS-NRS/EMBRAPA-CNPT, 1995. 224p.

COREY, R.B. Factors affecting the availability of nutrients to plants. In: WALSH, L.M. (Ed). Soil testing and plant analysis. Madison: SSSA, 1973. Cap.3, p.23-34.

ELTZ, F.L.F. et al. Efeitos de sistemas de preparo do solo nas propriedades físicas e químicas de um latossolo bruno álico. Revista Brasileira de Ciência do Solo, Campinas, v.13, p.259-267, 1989.

ELKHATIB, E.A. et al. A rapid centrifugation method for obtaining soil solution. Soil Science Society America Journal, Madison, v.51, n.3, p.578-583, 1987.

EMBRAPA. Centro Nacional de Pesquisa de Solos. Sistema Brasileiro de Classificação de Solos. Brasília: Embrapa, 1999. 412p.

HAVLIN, J.L. et al. Crop rotation and tillage effects on soil organic carbon and nitrogen. Soil Science Society America Journal, Madison, v.54, p.448-452, 1990.
LIMA, M.R. de. Dinâmica de nutrientes em função da calagem de solos arenosos. 1993. 112f. Dissertação (Mestrado em Agronomia) - Programa de Pós-graduação em Agronomia, Universidade Federal do Rio Grande do Sul.

MEURER, E.J. Disponibilidade de potássio para as plantas e sua relação com formas, mineralogia e cinética de liberação no solo. 1991. 137f. Tese (Doutorado em Agronomia) - Programa de Pós-graduação em Agronomia, Universidade Federal do Rio Grande do Sul.

MOORE, T.R. The spectrophotometric determination of dissolved organic carbon in peat waters. Soil Science Society America Journal, v.49, p.1590-1592, 1985.

MURPHY, J.; RILEY, J.P. A modified single solution method for the determination of phosphate in natural waters. Analytical Chimical Acta, Amsterdan, v.27, p.31-36, 1962.

SALET, R.L. Dinâmica de íons na solução de um solo submetido a diferentes sistemas de manejo. 1994. $110 \mathrm{f}$. Dissertação (Mestrado em Agronomia) - Programa de Pósgraduação em Agronomia, Universidade Federal do Rio Grande do Sul.

SILVA, L.S. Características químicas de um latossolo nos sistemas plantio direto e convencional no primeiro ano. 1996. 87f. Dissertação (Mestrado em Agronomia) Programa de Pós-graduação em Agronomia, Universidade Federal do Rio Grande do Sul.

SPOSITO, G. The chemistry of soils. New York: Oxford University, 1989. 277p.

TEDESCO, M.J. et al. Análises de solo, planta e outros materiais. 2.ed. Porto Alegre: Departamento de Solos, Faculdade de Agronomia, UFRGS, 1995. 174p. (Boletim Técnico, 5).

VARGAS, R.M.B. et al. Mecanismos de suprimento de fósforo, potássio, cálcio e magnésio às raízes de milho em solos do Rio Grande do Sul. Revista Brasileira de Ciência do Solo, Campinas, v.7, p.143-148, 1983.

WOOD, C.W. et al. Soil carbon and nitrogen changes on initiation of no-till cropping systems. Soil Science Society America Journal, Madison, v.55, p.470-476, 1991. 